\title{
Memperkenalkan Jenis Kerusakan Kertas dan Penanganan Konservasi Interventif Sederhana kepada Staf Museum-Museum di Yogyakarta
}

\author{
Mahirta \\ Departemen Arkeologi, Fakultas Ilmu Budaya, Universitas Gadjah Mada \\ Pos-el: mahirta.fib@ugm.ac.id
}

\begin{abstract}
Papers and old books are important part of museum collections in many museums in Yogyakarta, even some of them have very significant value and become masterpiece collections. Some old books such as from Islamic and colonial period have unique binding structures that should be preserved too as it become a historical marker. Therefore, special care for paper collections and old books should be carried out by museum conservator. Unfortunately, not all museums in Yogyakarta have professional conservator. Bear in mind that many museums in Yogyakarta has significant value of paper collection, a workshop of paper conservation was conducted on 18-19 September 2019 in Museum UGM, as a community service for museum communities in Yogyakarta. Through this workshop, participants managed to identify types of damage on paper collections, identify the cause of damage, and conduct simple interventive conservation.
\end{abstract}

Keywords: paper; old book; binding; conservation; skill

\begin{abstract}
Abstrak
Kertas dan buku tua merupakan bagian penting dari koleksi museum di banyak museum di Yogyakarta, bahkan beberapa memiliki nilai yang sangat penting dan menjadi koleksi istimewa. Beberapa buku tua, contohnya dari masa Islam dan kolonial, memiliki struktur jilid yang unik yang juga harus dilestarikan karena menjadi penanda sejarah. Maka dari itu, penanganan khusus untuk koleksi kertas dan buku tua harus dilakukan oleh konservator museum. Sayangnya, tidak semua museum di Yogyakarta memiliki konservator profesional. Mengingat bahwa banyak museum di Yogyakarta memiliki koleksi kertas dengan kandungan nilai penting, workshop konservasi kertas dilaksanakan pada 18-19 September 2019 di Museum UGM sebagai bentuk pengabdian masyarakat kepada komunitas museum di Yogyakarta. Melalui workshop ini, peserta berhasil mengidentifikasi tipe kerusakan dan penyebabnya pada koleksi kertas serta melakukan konservasi interventif sederhana pada koleksi kertas.
\end{abstract}

Kata kunci: kertas; buku tua; jilid; konservasi; keterampilan

\section{Pendahuluan}

Kertas merupakan koleksi museum yang sangat rentan terhadap kerusakan karena berasal dari bahan organik. Kelembapan yang tinggi, sinar/panas yang melebihi batas, dan hama merupakan musuh utama koleksi berbahan kertas, terlebih lagi jika ketiga unsur deteriorasi tersebut bergabung dan terakumulasi. Oleh karena itu, pencegahan dampak buruk ketiga unsur utama perusak kertas tersebut harus dilakukan karena 
beberapa jenis kerusakan yang sudah telanjur terjadi tidak dapat diperbaiki lagi.

Banyak museum di Daerah Istimewa Yogyakarta memiliki koleksi kertas, baik dalam bentuk lembaran maupun yang terjilid menjadi buku. Beberapa di antara koleksi kertas dan buku-buku tua yang dimiliki belum dikelola secara maksimal. Sangat kurangnya staf dengan keahlian dan keterampilan di bidang konservasi kertas dapat mengakibatkan koleksi museum menurun nilainya, antara lain, yakni karena berlubang dimakan serangga dan lembar-lembar kertas lengket karena ruang penyimpanan terlalu lembab. Seharusnya, penurunan nilai tersebut dapat diminimalkan jika seorang konservator dapat mengelola koleksi kertas yang dimiliki museum dengan baik.

Kegiatan workshop konservasi kertas ini dilaksanakan agar pengetahuan dan keterampilan konservasi kertas yang meliputi konservasi preventif dan konservasi interventif sederhana dapat dimiliki oleh staf museum-museum di Yogyakarta. Diharapkan keterampilan yang diperoleh selama workshop dapat diterapkan di museum masingmasing sehingga koleksi kertas yang dimiliki dapat terjaga dengan baik kondisinya.

Terkait dengan keinginan untuk menyebarkan keterampilan tambahan bagi staf-staf museum dalam mengenali jenis kerusakan kertas, mengenali jenis-jenis penyebabnya, dan mengetahui cara perbaikan sederhana, kami berminat untuk menyelenggarakan workshop ini di Yogyakarta bekerja sama dengan Barahmus Yogyakarta. Media workshop kami pilih karena dalam pelaksanaan workshop, peserta memperoleh bekal pengetahuan terkait dengan konservasi kertas secara teoretis terlebih dahulu dan diikuti dengan kegiatan berdiskusi serta mempraktikkan keterampilan secara berkelompok dan mandiri. Peserta juga melihat dan memegang sendiri tipe-tipe kerusakan kertas serta buku tua, belajar mengidentifikasinya, menentukan tindakan konservasi sederhana yang dapat dilakukan, dan yang penting, pada kegiatan workshop, peserta mempraktikkan langsung kegiatan konservasi interventif sederhana pada koleksi kertas.

Workshop diselenggarakan di Museum UGM yang saat ini berada di bawah pengelolaan dan dikelola bersama antara Direktorat Penelitian dan Pengabdian kepada Masyarakat UGM serta Fakultas Ilmu Budaya UGM.

\section{Pelaksanaan Program}

\section{Tabap Persiapan}

1. Survei beragam kondisi koleksi kertas

Dilaksanakan di beberapa museum di DIY yang disebarkan via media elektronik. Demikian pula ragam kerusakan koleksi berbahan kertas dan naskah-naskah yang telah dijilid menjadi buku berumur tua. Selain memberikan pengetahuan baru secara teoretis, materi workshop juga disusun berdasarkan kondisi yang ditemukan di museum-museum.

\section{Menyusun materi workshop}

Penyusunan materi workshop dilakukan bekerja sama dengan narasumber yang diundang untuk menyampaikan materi, baik secara teoretis maupun praktik bersama. Kedua pembicara tersebut adalah Ery Sustiyadi, S.T., M.A., sebagai spesialis konservator kertas dan Asies Sigit Pramujo, S.S., M.A yang akan memberikan materi dan praktik terkait dengan pembuatan laporan kondisi koleksi. Koordinator pelaksana workshop, 
Dr. Mahirta, M.A. memberikan materi terkait dengan rangkaian pemeliharaan koleksi di museum. Hal ini diperlukan karena aktivitas terkait dengan manajemen koleksi saling berhubungan satu dengan lainnya secara terintegrasi.

Secara garis besar, materi yang direncanakan terbagi menjadi tiga, yaitu (a)aktivitas-aktivitas yang terkait dengan pemeliharaan koleksi, (b)pembuatan laporan kondisi koleksi, dan (c)konservasi koleksi kertas.

Materi workshop tersebut kemudian dikembangkan menjadi buku saku yang

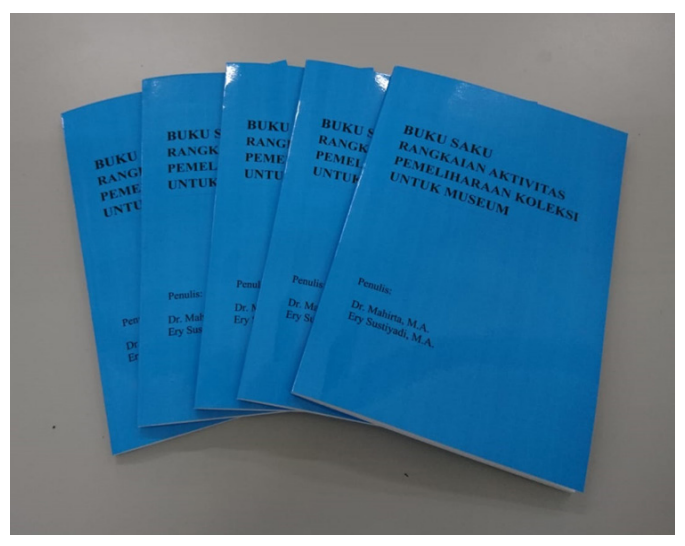

Gambar 1. Buku saku Rangkaian Aktivitas Pemeliharaan Koleksi untuk Museum. (Sumber: Dok. Fayeza Shasliz Arumdhati) berjudul Buku Saku Rangkaian Aktivitas

Pemeliharaan Koleksi untuk Museum. Selain diberikan kepada peserta, buku saku akan dibagikan kepada museum-museum yang tidak mengirimkan peserta sebagai pedoman pelaksanaan konservasi interventif sederhana sehingga pengetahuan praktis ini dapat lebih tersebar luas.

\section{Perekrutan peserta}

Peserta direkrut dari staf tetap anggota Barahmus Yogyakarta. Status staf tetap perlu dicantumkan sebagai persyaratan peserta workshop karena pengiriman staf tidak tetap museum akan kurang memberikan manfaat pada museum masing-masing. Staf tidak tetap keluar setelah mereka mendapat pekerjaan tetap di tempat lain dan keterampilan yang telah diperoleh melalui workshop sering kali tidak termanfaatkan. Karena antusiasme para pimpinan museum anggota Barahmus untuk mengikutsertakan stafnya dalam kegiatan workshop ini, jumlah peserta ditingkatkan dari target yang direncanakan dalam proposal, yang semula hanya 15 peserta menjadi 30 orang peserta. Karena keterbatasan biaya, jumlah hari pada workshop juga dukurangi dari 3 hari menjadi 2 hari, dengan tidak mengurangi kualitas materi workshop yang disampaikan, tetapi durasi waktu pelaksanaan workshop diperpanjang.

\section{Tabap Pelaksanaan}

Workshop diselenggarakan di Museum UGM pada 18 dan 19 September 2020. Kegiatan workshop meliputi pemberian materi teoretis dan praktik. Pelaksanaan workshop dibantu oleh konservator kertas Museum Sonobudoyo dan seorang konservator Museum UGM sebagai pemberi materi dan pembimbing praktik.

Peserta yang mengikuti workshop terdiri atas beberapa museum yang ada di Yogyakarta, yaitu staf dari 21 museum dan mahasiswa Departemen Arkeologi dengan jumlah keseluruhan yang terlibat dalam workshop 30 orang.

Koordinator workshop memberikan materi yang mengenalkan prinsip kerja konservasi dan rangkaian aktivitas di museum yang terkait dengan pemeliharaan koleksi. Praktik yang diselenggarakan pada saat workshop ialah praktik pengisian laporan kondisi (condition report), khususnya koleksi kertas, dan praktik menstabilkan kondisi kertas 
Tabel 1. Peserta Workshop

\begin{tabular}{|c|c|c|}
\hline No. & Institusi/Museum & Jumlah Peserta \\
\hline 1. & Mahasiswa Departemen Arkeologi Prodi S1 & 2 orang \\
\hline 2. & Museum Sandi & 1 orang \\
\hline 3. & Museum Tembi Rumah Budaya & 1 orang \\
\hline 4. & Museum Ullen Sentalu & 1 orang \\
\hline 5. & Museum Affandi & 1 orang \\
\hline 6. & Museum Tani & 1 orang \\
\hline 7. & Museum TNI-AU Dirgantara Mandala & 1 orang \\
\hline 8. & Museum Pendidikan Indonesia - UNY & 1 orang \\
\hline 9. & Museum Benteng Vredeburg Yogyakarta & 1 orang \\
\hline 10. & Museum Kraton Yogyakarta & 1 orang \\
\hline 11. & Museum Biologi & 1 orang \\
\hline 12. & Museum Angkatan Darat & 1 orang \\
\hline 13. & Museum Monumen Yogya Kembali & 1 orang \\
\hline 14. & Museum Dewantara Kirti Griya & 1 orang \\
\hline 15. & Museum Gempa Prof. Sarwidi & 1 orang \\
\hline 16. & Museum Dr. Yap & 1 orang \\
\hline 17. & Museum Laboratorium Sejarah UPY & 1 orang \\
\hline 18. & Museum Taman Tirto Sidin & 1 orang \\
\hline 19. & Museum Pergerakan Wanita Indonesia & 1 orang \\
\hline 20. & Museum Geo Teknologi Mineral & 1 orang \\
\hline 21. & Museum History of Java & 1 orang \\
\hline 22. & Museum Batik & 1 orang \\
\hline 23. & Museum UGM & 7 orang (termasuk narasumber) \\
\hline
\end{tabular}

yang sobek dengan menggunakan kertas jepang dan memperbaiki jilid buku kuno.

Materi berupa rangkaian aktivitas yang terkait dengan pemeliharaan koleksi di museum adalah sebagai berikut.

1. Penjelasan mengenai manajemen koleksi (collection management)

Keseluruhan aktivitas yang dilaksanakan mulai dari perolehan objek sebagai koleksi museum (melalui hibah, pembelian, lelang) sampai dengan koleksi tersebut diregistrasi, disimpan di dalam storage, dikonservasi, dimanfaatkan dengan cara dipamerkan di museum sendiri atau di tempat lain, dikaji, atau diteliti sampai dengan kemungkinan koleksi tersebut dikeluarkan dari koleksi museum melalui pertimbangan-pertimbangan yang matang.

2. Pemaparan pentingnya kerja sama antara konservator, kurator, dan registrator dalam mengelola koleksi pada masing-masing tahapan tersebut. Ditekankan bahwa di dalam setiap tahapan pengelolaan koleksi tersebut di atas, terdapat persinggungan dengan aktivitas pemeliharaan/perawatan koleksi yang meliputi berbagai tingkatan aktivitas konservasi (konservasi preventif sampai dengan restorasi).

3. Penjelasan bahwa ada beberapa aktivitas penting yang terkait dengan pemeliharaan koleksi: 
Aktivitas-aktivitas tersebut dapat dikelompokkan dalam tindakan konservasi inti yang bersifat preventif dan interventif, tetapi ada pula aktivitas yang kurang terkait dengan koleksi secara langsung tetapi sangat berpengaruh, misalnya keselamatan kerja staf. Koleksi perlu dirawat dan dicegah dari kerusakan, tetapi keselamatan kerja staf yang menangani koleksi juga perlu diperhatikan.

Aktivitas yang lebih dekat hubungannya dengan pemeliharaan koleksi ialah penyediaan informasi koleksi dan panduan akses terhadap koleksi. Termasuk dalam penyediaan informasi koleksi adalah pembuatan katalog koleksi, pengklasifikasian koleksi, pengontrolan lokasi dan pergerakannya, mendeskripsikan koleksi, menginventarisasikan koleksi, mengelola akses terhadap koleksi, dan mengelola informasi mengenai koleksi (Art and Council England, tt).

4. Penjelasan contoh-contoh aktivitas yang terkait dengan pemeliharaan koleksi yang terdiri atas pengecekan kondisi koleksi, prioritas pelaksanaan konservasi, pengontrolan hama, pembuatan rencana penanggulangan bencana, penjaminan keselamatan kerja, pemindahan objek koleksi, mengasuransikan koleksi, memonitor lingkungan, dan pelaksanaan keamanan di museum.

Materi tentang pengenalan macam-macam kerusakan kertas diberikan oleh Ery Sustiyadi, S.T., M.A. dengan menunjukkan contoh-contoh kerusakan berupa warna kertas yang berubah, kertas berlubang karena dimakan serangga, jahitan dan jilidan rusak, sampul rusak, kertas menjadi rapuh dan tinta tembus pada halaman sebaliknya, dan menyebabkan kertas berlubang. Materi tersebut diikuti dengan pengenalan jenisjenis kerusakan kertas yang terdiri atas (Mahirta dan Sustiyadi, 2019):

1. Faktor Internal

- Bahan kertas terbuat dari selulosa dan lignin sebagai sumber makanan bagi serangga.

- Perekat atau lem yang digunakan biasanya dari bahan organik berupa gandum, pati, atau kanji. Bahan tersebut juga merupakan sumber makanan bagi serangga.

- Pada proses pembuatan biasanya menggunakan bahan-bahan kimia yang mengandung asam sehingga keasaman ini juga akan merusak koleksi kertas.

- Tinta yang digunakan pada zaman dulu biasanya dari bahan karbon atau jelaga yang tidak merusak kertas. Akan tetapi, seiring dengan kebutuhan tinta yang banyak, diproduksilah tinta yang mengandung feri sulfat. Tinta yang mengandung feri sulfat inilah yang akan merusak koleksi kertas.

2. Faktor Eksternal

- Faktor alam terdiri atas sinar ultraviolet dan intensitas cahaya yang akan merusak koleksi kertas. Paparan ultraviolet yang berlebihan akan mengakibatkan warna kertas berubah menjadi kekuning-kuningan. Kerusakan ini sifatnya akumulatif dan tidak dapat dikembalikan seperti semula, sedangkan intensitas cahaya akan mengakibatkan rantai karbon pada kertas menjadi putus dan ini mengakibatkan kertas menjadi rapuh.

- Faktor biologi terdiri atas serangga, binatang pengerat, dan jamur.

- Temperatur dan lembapan yang tidak tepat.

- Polutan. 


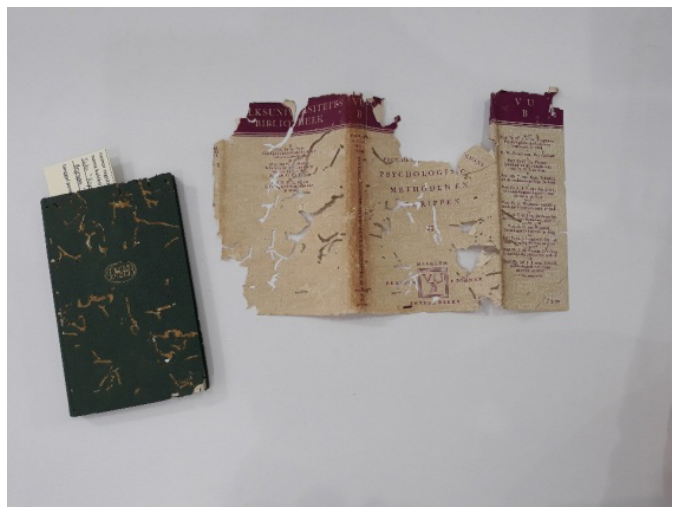

Gambar 2. Contoh Kerusakan Koleksi Kertas akibat Serangga (Sumber: Dok. Mahirta)
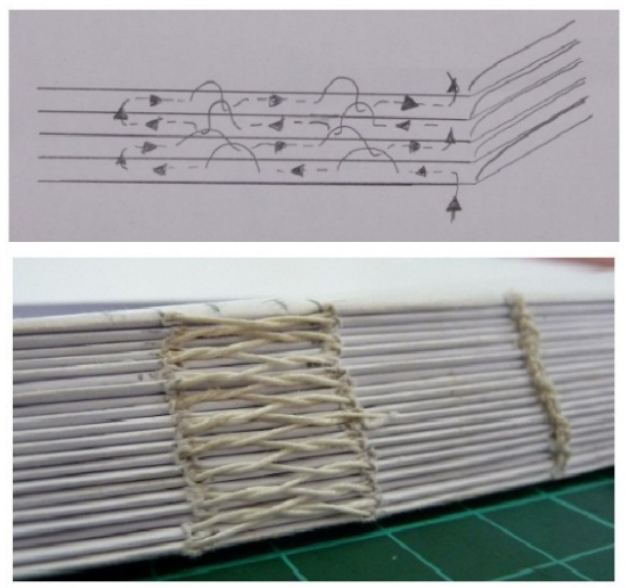

Gambar 4. Teknik Penjilidan dengan Model Jahitan Kupu-kupu, Skema Jahitan (atas), dan Contoh Koleksi dengan Jahitan Kupu-kupu (bawah)

(Sumber: Dok. Eri Sustiyadi)

B
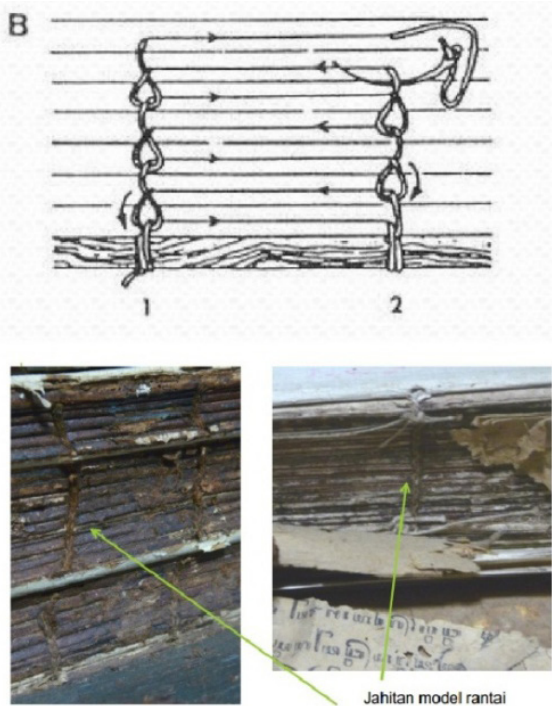

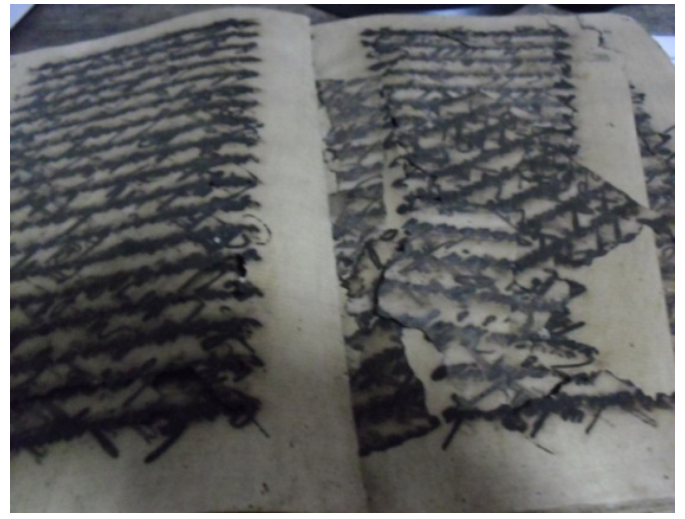

Gambar 3. Contoh Kerusakan Koleksi Kertas Berupa Tinta Tembus (Sumber: Dok. Eri Sustiyadi)
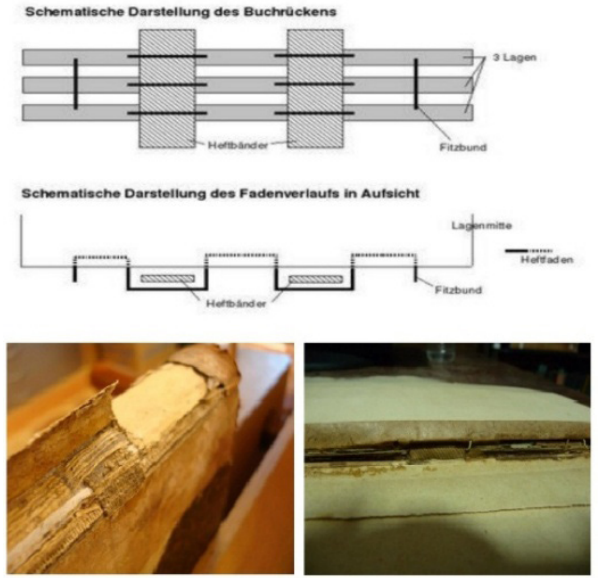

Gambar 5. Teknik Penjilidan dengan Model Jahitan Menyeluruh, Skema Jahitan (atas), dan Contoh Koleksi dengan Jahitan Menyeluruh (bawah)

(Sumber: Dok. Eri Sustiyadi)

Gambar 6. Teknik Penjilidan dengan Model Rantai, Skema Jahitan (atas), dan Contoh Koleksi Buku dengan model Rantai (bawah) (Sumber: Dok. Eri Sustiyadi) 
Pada pengenalan macam-macam model jilid buku diberikan beberapa contoh model jilidan seperti yang tertera pada gambar 4-6 di atas (Mahirta dan Sustiyadi, 2019: gb 11).

Ketika melakukan restorasi jilidan pada buku tua, model jilid sedapat mungkin dikembalikan seperti model jahitan jilid semula karena di samping memiliki nilai intangible, beberapa koleksi buku tua, seperti misalnya dari masa Islam dan periode kolonial, memiliki struktur jilid yang unik, yang juga harus dilestarikan karena struktur jilid yang unik tersebut menjadi penanda sejarah yang penting, yang meliputi penanda zaman dan negara asal.

\section{Materi Praktik}

Dalam pelaksanaan praktik konservasi interventif sederhana pada koleksi berbahan kertas,

- peserta workshop diperkenalkan pada bahan-bahan yang diperlukan, yaitu:

- perekat (CMC/Carboxyl Metyl Celulosa, WSP/wheat starch paste, kanji)

- kertas jepang (sesuaikan dengan ketebalan dan warna koleksi kertas yang akan dikonservasi)

- blotting paper (untuk menyerap kandungan air pada perekat)

- bondina paper (untuk melapisi pada bagian koleksi agar tidak melekat)

- sreen

- bone folder (untuk menekan dan meratakan)

- pemberat

- kuas kecil dan besar.

Peserta kemudian mempraktikkan prosedur menambal kertas berlubang dengan prosedur sebagai berikut (Mahirta dan Sustiyadi, 2019:35-36).

- Membuat lapisan bawah dari blotting paper

- Meletakkan bondina paper di atas blotting paper

- Meletakkan objek/koleksi yang akan ditambal

- Menutup/tambal bagian koleksi yang berlubang menggunakan kertas jepang yang sudah diberi perekat menggunakan kuas kecil

- Menutup bagian yang ditambal dengan bondina paper dan blotting paper

- Meratakan dan menekan kertas dengan folder tanduk atau tulang

- Meletakkan pemberat untuk mengeringkan dan biarkan hingga 24 jam

- Membuka perlahan pemberat dan lapisan blotting paper dan bondina paper

Praktik ketiga yang dilaksanakan dalam workshop adalah praktik mengisi form laporan kondisi koleksi (terkait dengan pembuatan laporan kondisi koleksi) karena untuk praktik merencanakan, me-monitoring, dan mengontrol kegiatan konservasi kertas memerlukan waktu lebih lama dan dirasa terlalu kompleks untuk pemula sehingga praktik disederhanakan.

\section{Refleksi Capaian Program}

Workshop konservasi kertas pada tahun 2019 diikuti oleh staf anggota Barahmus dan 2 orang mahasiswa yang berminat di bidang konservasi koleksi museum. Penambahan 

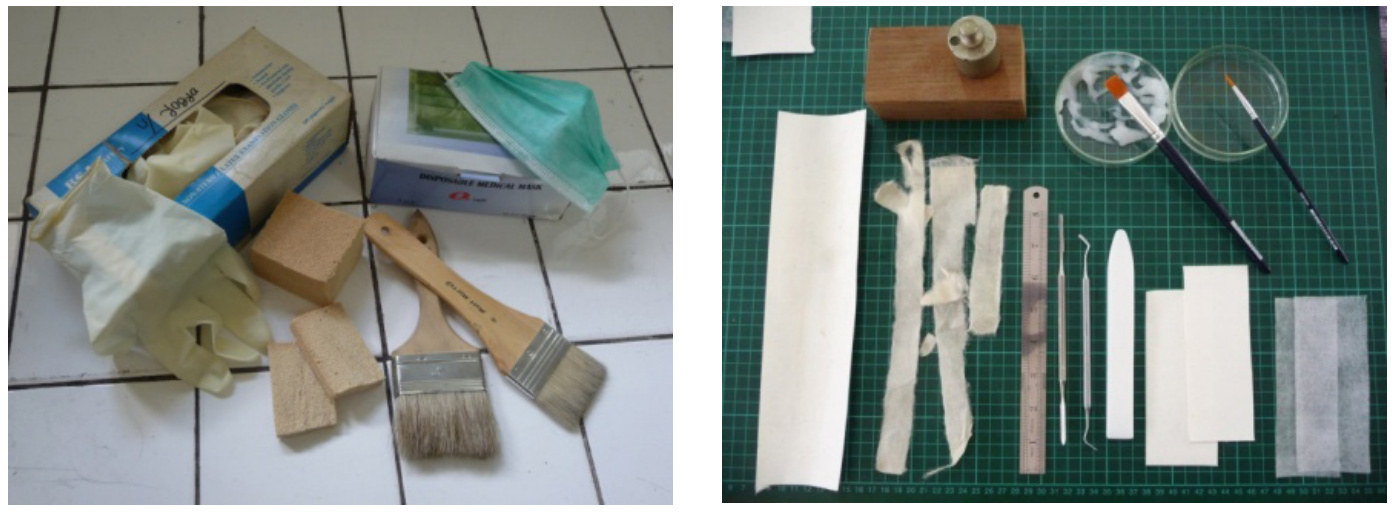

Gambar 7. Peralatan yang Digunakan dalam Kegiatan Konservasi Koleksi Kertas (Sumber: Dok. Eri Sustiyadi)
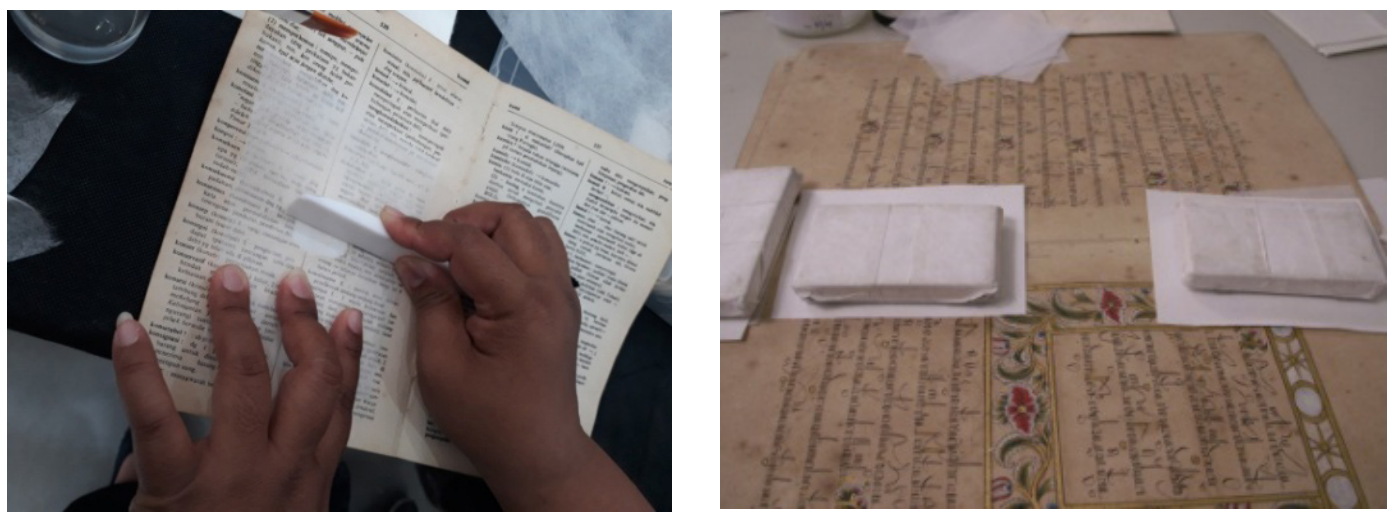

Gambar 8. Contoh Tindakan Menambal Bagian Berlubang pada Koleksi Kertas

(Sumber: Dok. Eri Sustiyadi)

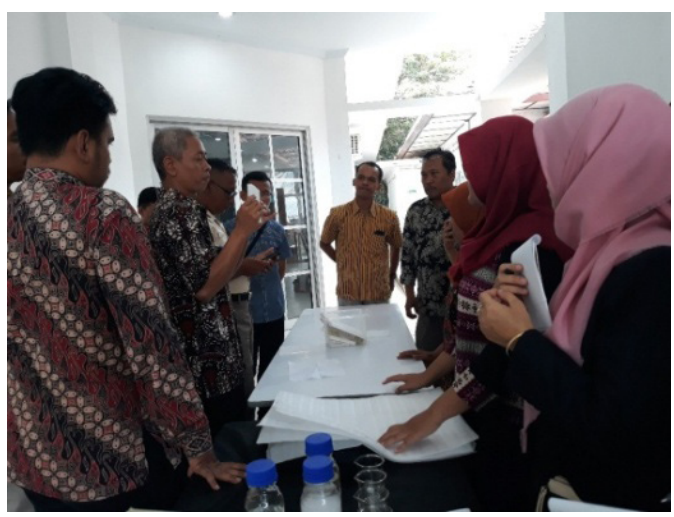

Gambar 9. Praktik Konservasi Penambalan Lubang Kertas dan Perbaikan Jilid (Sumber: Dok. Mahirta)

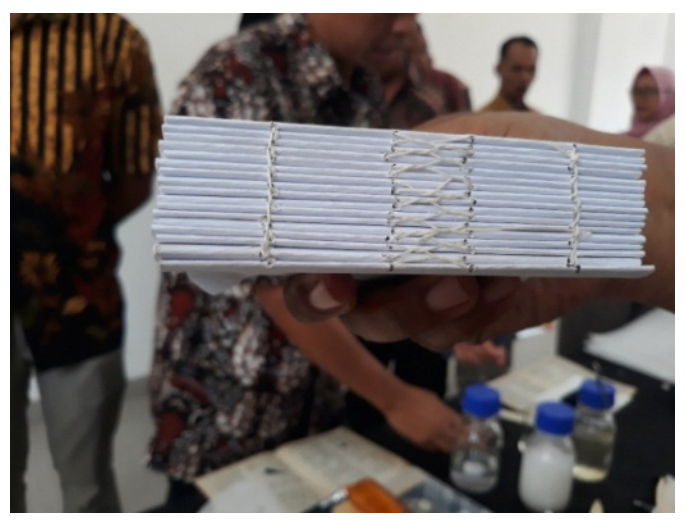

Gambar 10. Hasil Pembuatan Jahitan Jilid Buku Oleh Peserta pada Sesi Praktik Konservasi Kertas (Sumber: Dok. Mahirta) 
jumlah peserta mahasiswa yang berminat dirasa perlu karena kemungkinan mereka yang akan melaksanakan aktivitas-aktivitas konservasi di museum-museum pada waktu yang akan datang. Meskipun selama praktik terbimbing dengan bimbingan tutor dan saling meniru antarpeserta, peserta workshop dapat melaksanakan proses penambalan dan meniru penjilidan buku tua, ada kemungkinan prosedur itu tidak diingat lagi oleh peserta workshop ketika mereka harus mempraktikkannya sendiri di museumnya masingmasing. Oleh karena itu, pada masa yang akan datang, penambahan materi berupa video pendek dan pendokumentasian pelaksanaan praktik dalam bentuk video akan sangat berguna jika peserta akan mempraktikkannya sendiri di museumnya masing-masing dan akan menularkan keterampilan barunya kepada staf lain.

\section{Penutup}

Antusiasme peserta untuk datang mengikuti workshop konservasi kertas menunjukkan bahwa keinginan masing-masing museum untuk meningkatkan kemampuan stafnya dalam pemeliharaan koleksi, khususnya koleksi kertas dan buku tua. Melalui workshop yang dilaksanakan, peserta telah mampu mengidentifikasi jenis-jenis kerusakan pada koleksi kertas dan mengidentifikasi kemungkinan penyebab kerusakannya sehingga dapat dihindarkan. Praktik singkat telah membimbing setiap peserta agar dapat melakukan penambalan kertas berlubang dan merestorasi model jilid sederhana. Praktik terakhir ini dikategorikan sebagai tindakan konservasi interventif. Keterampilan sebaiknya diperdalam terlebih dahulu dengan mencobanya beberapa kali pada replika sebelum diterapkan pada koleksi sebenarnya. Diharapkan workshop konservasi interventif lanjutan akan dilaksanakan pada masa mendatang.

Museum UGM sebagai salah satu museum Universitas di Yogyakarta merupakan institusi penting dalam penyebaran keterampilan tekait dengan aktivitas-aktivitas di bidang permuseuman. Hal ini terkait dengan peran museum universitas yang juga seharusnya dapat memberikan manfaat kepada masyarakat luas, tidak hanya melalui koleksi-koleksi yang dipamerkan, tetapi juga melalui pelatihan-pelatihan di bidang permuseuman yang diberikan oleh para dosen dan mahasiswa terkait dengan aktivitas profesi di bidang permuseuman. Penyelenggaraan workshop di Museum UGM juga sekaligus mempromosikan salah satu aktivitas unggulan Museum UGM, yaitu pelatihan untuk meningkatkan kemampuan terkait dengan profesi di bidang permuseuman.

\section{Daftar Pustaka}

Ambrose, T. dan Crispin P. (2006). Museum Basics 2nd Edition. London: Routledge. Art Council England. (2017). Arts Council Collection Care \& Conservation Policy \& Conservation Plan.

Art Council England. (2013). A Practical Guide. Security in Museums and Galleries. England: Collection Trust.

Heritage Collections Council. (2001/2002). Guidelines for Environmental Control in Cultural Institutions. Consortium for Heritage Collections and their Environment for the Conservation and Collections Management Working Party of the Heritage Collections Council. 
Mahirta dan Ery S. (2019). Buku Saku Rangkaian Aktivitas Pemeliharaan Koleksi untuk Museum. Yogyakarta: Fakultas Ilmu Budaya Universitas Gadjah Mada dan Museum UGM. Tidak diterbitkan.

Museum WA.gov.au. Museum Security. Diakses pada 15 Oktober 2019.

Museums Australia Inc (NSW). (2002). Museum Methods: A practical guide for managing small museums and galleries. Section 1.1 Starting a museum

National Park Service. (1994). An Insect Pest Control Procedure: The Freezing Process. Conserve O Gram. Volume 3 (6).

Pinniger, D. dan Peter W. (2004). Integrated Pest Management: A guide for museums, libraries and archives. London: Museums, Libraries and Archives Council.

PP No. 66 Tahun 2015 tentang Peruseuman.

Renick, M. (2011, July 1). Sample Condition Reports. CIDOC 211 Condition Reports: Reporting Damage and Loss. Lubbock, Texas: United States of America.

The Council for Museums, Archives and Libraries. (2003). Security for Museum, Archives and Galleries, A practical Guides. London: The Council for Museums, Achives and Libraries.

\section{Ucapan Terima Kasih}

Terima kasih kepada staf Museum UGM yang telah ikut mempersiapkan pelaksanaan workshop di Museum UGM dan kepada Fayeza Shasliz Arumdhati yang telah membantu me-layout artikel serta buku saku materi workshop. 